\title{
E-cigarettes, smokers and health policies
}

\author{
S. Nardini1, R. Pacifici2
}

Monaldi Arch Chest Dis 2013; 79: 6-7.

Keywords: E-cigarettes, Health, Smoking.

1 UO di Pneumotisiologia, ULSS 7, Regione Veneto, Vittorio Veneto (TV),

2 Osservatorio Fumo Alcol e Droga (OSSFAD), Istituto Superiore di Sanità, Roma, Italy.

Stefano Nardini, Pulmonary and TB Unit, Vittorio Veneto General Hospital, Viale Forlanini, 71 - 31029 Vittorio Veneto (TV) Italy; e-mail: snardini@qubisoft.it.

The diffusion and consumption of Electronic cigarettes (called Electronic Nicotine Delivery Systems- ENDS [1]) is steadily increasing worldwide [2]. ENDS are marketed with the implicit promise that they are equally or more satisfying and much less dangerous (if not harmless) than traditional cigarettes, which has led to physicians frequently being asked about the usefulness and safety of ENDS.

In order to adequately respond to their patients, health professionals need to obtain some information about ENDS:

1. Can ENDS be defined as a single product like traditional cigarettes?

2. Is it possible to refer even to a single brand of ENDS as a standardised product, and predict effects when used?

3. Can ENDS be used as a smoking cessation drug?

4. Do we know if ENDS are a harmless substitute for traditional cigarettes?

The latter two questions give rise to two further enquiries:

5. Is the efficacy of ENDS (as for nicotine delivery) actually established?

6. Is the safety of ENDS (in relation to the adverse effects on human health) completely proven?

This information is necessary in order for physicians to give good medical advice when asked and to help stakeholders to preserve or promote the health of the community.

As a matter of fact, to date, the answers to these questions are all "no".

Let's look at why this is the case.

First, the characteristics of ENDS are extremely variable: they are all built on the same principle: a battery-operated heating device which heats and vaporises the content of a disposable cartridge (containing flavour, nicotine and other chemicals) to produce a vapour which can be inhaled like the smoke of a cigarette. Most ENDS are built to resemble a cigarette, both in form and in dimensions and it is possible to put different contents in the same device, to satisfy the wishes of the consumer.

However, among the cartridges (or among solutions which can be inside them), some do contain nicotine and some do not; it is worth noting that even cartridges labelled as containing no nicotine, can contain nicotine in measurable quantity [3].

Using the nicotine containing devices, the delivery of nicotine can vary 30 -fold, spanning from 0.5 to $15.4 \mathrm{mg}$ (referring to the total level in vapour generated by 20 series of 15 puffs) [4].

As a whole, however, e-cigarettes deliver less nicotine than a traditional cigarette, with a kinetic more similar to a Nicotine Replacement Therapy (NRT) device like the inhaler [5].

Such a big difference in the amount of nicotine delivered by different devices (and sometimes differences have been detected in the same ones-3) the effects of ENDS on health can be largely unpredictable.

Since there are no randomised controlled trials on ENDS for smoking cessation they should not be used as a drug for this purpose.

The components of ENDS have been measured by the Food and Drug Administration [3]: diethylene glycol, nitrosamines, tobacco-specific impurities, possibly harmful to humans, were found. Consequently, the use of ENDS cannot be considered as "harmless".

On the basis of this evidence we can assume that it is probable (because in ENDS tobacco is not burnt - however this assumption should be experimentally confirmed by a regulatory agency and laboratory) that ENDS cause less harm than traditional cigarettes but that it is equally probable that they are more dangerous than nicotine inhalers, since the latter have been designed and approved for pharmacological treatment.

For the whole body of available information it has been suggested that ENDS should be removed from the market until the problems related to lack of standardisation, lack of adequate labelling, absence or insufficiency of quality controls and, last but not least, health issues will be worked out [6] and indeed some Countries like Canada, Australia or Denmark has banned ENDS [1].

For these reasons (and also for emerging evidences that ENDS can negatively affect the respiratory system-[7]) physicians should be very cautious and rely on established smoking cessation drugs rather than using ENDS for this purpose. 
But why, if the state of the art is what has been shortly described and there is no evidence regarding the role of ENDS in helping smokers to quit and no systematic monitoring of adverse effects of ENDS has been carried out, do so many smokers use them, much more than the ones who use NRT or Varenicline [2]?

An examination of the Italian situation can help to answer this question.

According to the 2012 National report on tobacco smoking of the National Institute Of Health (ISS) [8] currently, in Italy, there are 10,8 million of active smokers, smoking a mean of 13 cigarette per day. One fourth of them (23\%) reported a quitting attempt. Even if this percentage is decreasing over the last 6 years, it still represents 2.5 million people. Health problems and concerns are reported as the two main reasons for the quitting attempt (43.7\% and $32.9 \%$ respectively, while economical reasons, fourth in rank after pregnancy, are reported by $3,4 \%$ ). At least one sixth of Italian smokers think seriously about starting a quitting attempt in the next six months. While only $4 \%$ of Italian smokers had received the advice from their general practitioner about the possibility of being treated in a smoking cessation clinics and only $32.9 \%$ know that these clinics exist, a substantial $75 \%$ of Italian smokers have had information about ENDS and $7.3 \%$ had used it while $12,4 \%$ think to try it in the future.

The big gap which exists between information and use of smoking cessation facilities and ENDS can probably be explained with different marketing strategies.

Conversely, even if in Italy we have one of the best smoking ban [8], according to the cited report [8] only $0.8 \%$ of smokers refers the smoking ban as a reason for the quitting attempt.

So, it seems clear that the reasons why ENDS are increasingly sold in Italy are less the possibility of using them even in an environment where smoking is prohibited than concerns about the effects of smoking on own health (concern leading to the search for a "safer" way of getting nicotine) and a lack of knowledge of smoking cessation helps in Italy.

In Italy there are [9] 380 smoking cessation clinics, 295 of the National Health Service and 85 of a charity (Lega Italiana per la Lotta contro i Tumori). The number seems adequate to the population needs (more or less one clinic per 160.000 inhabitants) but since most of these clinics are not formally constituted, have insufficient economic resources and do not have enough staff (most of whom work on a voluntary basis), the interventions are delivered to few smokers (meanly 86 patients per year per clinic).

According to the staff of these clinics, besides the training of other health professionals to first level interventions for tobacco dependence and to screen smokers to be referred to the clinic, the most important problem to work out is the "marketing" of the clinic and the "official" acknowledgement of its role.
As a whole, this data suggests that there is in Italy a strong demand for smoking cessation (and/or smoking reduction) which is not met by an adequate offer of the National Health Service: the mean number of smoker assisted by the Italian $\mathrm{Na}-$ tional Health Service (i.e. except patients assisted by the cited charity) for cessation is some 25.000. This poor offer can explain the business of ENDS. Which is big: founded in 2008, in a single year (2010) the company which is at the top of the sector in Italy has produced 250,000 kits of e-cigarettes and over 3 million cartridges [10].

In conclusion, most of e-cigarettes seems to be used as a self medication by smokers. Since there are no restrictions to their trade, their diffusion is wider (and will be further wider) than smoking cessation treatment.

It is debatable if a Government or a NHS, committed to the health of the community, can accept that the population try to self-manage a disease (like smoking is) with "drugs" not studied and not approved for this use, simply because the proper treatment for smoking cessation has not been implemented and marketed.

The striking success of ENDS in every Country is a challenge to the Governments and their Regulatory Agencies: to meet smoker's needs, ENDS should be strictly regulated and adequate treatment for tobacco dependence widely implemented, according to the art. 14 of the Framework Convention for Tobacco Control of the WHO [11].

\section{References}

1. WHO Study Group on Tobacco Product RegulationReport on the Scientific Basis of Tobacco Product Regulation WHO Technical Report Series, no. 955, Fourh edition, February 2012.

2. Ayers JW, Ribisl KM, Brownstein JS. Tracking the rise in popularity of electronic nicotine delivery systems (electronic cigarettes) using search query surveillance. Am J Prev Med 2011; 40: 448-53.

3. Westenberger BJ. Evaluation of e-cigarettes. St Louis, MO: US Food and Drug Administration, Center for Drug Evaluation and Research; 2009.

4. Goniewicz ML, Kuma T, Gawron M, Knysak J, Kosmider L. Nicotine Levels in Electronic Cigarettes Nicotine. Tob Res 2012; doi: 10.1093/ntr/nts103

5. Bullen C, McRobbie H, Thornley S, Glover M, Lin R, Laugesen $\mathrm{M}$. Effect of an electronic nicotine delivery device (e cigarette) on desire to smoke and withdrawal, user preferences and nicotine delivery: randomised cross-over trial. Tob Control 2010; 192: 98-103.

6. Trtchounian and Talbot, Electronic nicotine delivery systems: is there a need for regulation? Tob Control doi:10.1136/tc.2010.037259.

7. Vardavas CI, Anagnostopoulos N, Kougias M, Evangelopoulou V, Connolly GN, Behrakis PK. Short-term pulmonary effects of using an electronic cigarette: impact on respiratory flow resistance, impedance, and exhaled nitric oxide. Chest 2012 Jun; 141 (6): 1400-6.

8. Joossens L, Raw M. The Tobacco Control Scale: a new scale to measure country activity. Tob Control 2006; 15: 247-253.

9. http://www.iss.it/fumo/rann/cont.php?id=283\&lang $=1 \&$ tipo $=3$

10. http://www.categoriagroup.com/UK/c_profile.html

11. http://whqlibdoc.who.int/publications/2003/9241591013.pdf 